\title{
Payload charging events in the mesosphere and their impact on Langmuir type electric probes
}

\author{
T. A. Bekkeng ${ }^{1}$, A. Barjatya ${ }^{2}$, U.-P. Hoppe ${ }^{1, *}$, A. Pedersen ${ }^{1}$, J. I. Moen ${ }^{1}$, M. Friedrich ${ }^{3}$, and M. Rapp ${ }^{4, * *}$ \\ ${ }^{1}$ University of Oslo, P.O. Box 1048, Blindern 0316, Norway \\ ${ }^{2}$ Embry-Riddle Aeronautical University, 600 S. Clyde Morris Blvd., Daytona Beach, FL 32114, USA \\ ${ }^{3}$ Institute of Communication Networks and Satellite Communications, Graz University of Technology, Graz, Austria \\ ${ }^{4}$ Leibniz-Institute of Atmospheric Physics, Kühlungsborn, Germany \\ * on leave from: Norwegian Defence Research Establishment (FFI), Kjeller, Norway \\ *** now at: Deutsches Zentrum für Luft- und Raumfahrt, Institut für Physik der Atmosphäre, Wessling, Germany
}

Correspondence to: T. A. Bekkeng (t.a.bekkeng@ fys.uio.no)

Received: 23 August 2012 - Revised: 28 November 2012 - Accepted: 7 January 2013 - Published: 7 February 2013

\begin{abstract}
Three sounding rockets were launched from Andøya Rocket Range in the ECOMA campaign in December 2010. The aim was to study the evolution of meteoric smoke particles during a major meteor shower. Of the various instruments onboard the rocket payload, this paper presents the data from a multi-Needle Langmuir Probe (m-NLP) and a charged dust detector. The payload floating potential, as observed using the m-NLP instrument, shows charging events on two of the three flights. These charging events cannot be explained using a simple charging model, and have implications towards the use of fixed bias Langmuir probes on sounding rockets investigating mesospheric altitudes. We show that for a reliable use of a single fixed bias Langmuir probe as a high spatial resolution relative density measurement, each payload should also carry an additional instrument to measure payload floating potential, and an instrument that is immune to spacecraft charging and measures absolute plasma density.
\end{abstract}

Keywords. Ionosphere (Instruments and techniques) Space plasma physics (Numerical simulation studies; Spacecraft sheaths, wakes, charging)

\section{Introduction}

The ECOMA 7, 8 and 9 campaign's primary objective was to study the evolution of meteoric smoke particles (MSP) during a major meteor shower. To do this three sounding rockets were launched from the Andøya Rocket Range in De- cember 2010 , to an altitude of typically $135 \mathrm{~km}$; before, at, and after the peak meteor activity by the Geminids. Amongst an extensive instrumentation suite, each of the payloads carried: (a) a charged dust detector in the payload under the ejectable nose cone, (b) a fixed bias electron probe (FEP), (c) a Faraday rotation experiment, (d) the Combined Observations of Neutrals and Electrons (CONE) instrument, and (e) a novel multi-Needle Langmuir Probe (m-NLP). In this paper we first provide a background introduction and references to Langmuir probes, and then subsequently present and discuss data from the m-NLP instrument.

Ever since the seminal work of Mott-Smith and Langmuir (1926), the Langmuir Probe has been extensively used as a space plasma diagnostic tool (for a recent review, see for instance Brace, 1998; see also Chapkunov et al., 1976, and Barjatya et al., 2009). Langmuir probes have also been used for measurement of plasma density and temperature in laboratory plasma (Braithwaite and Franklin, 2009). A Langmuir probe instrument operates by placing an exposed conductor in a plasma, biasing it with reference to the platform potential, and measuring the collected current from the exposed conductor. A representative response of a Langmuir probe is shown in Fig. 1. The collected current in saturation regions is a function of plasma density, and the collected current in the retardation region is dependent on electron temperature. As shown in the figure, payload floating potential $\left(V_{\mathrm{f}}\right)$ is the equilibrium potential attained by a conductive body immersed in a plasma, such that the total current from electrons and ions to the conducting surface sums to 


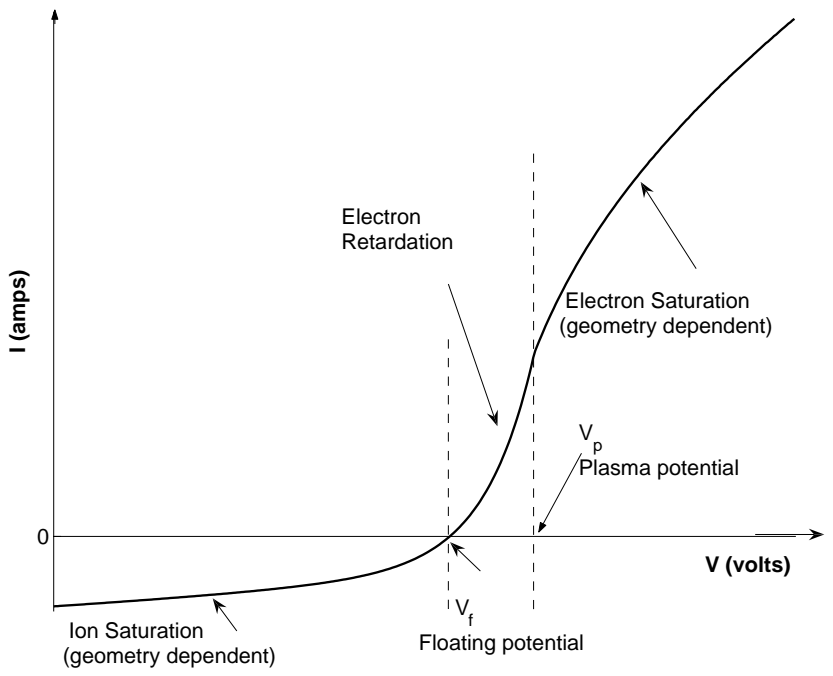

Fig. 1. I-V curve for a Langmuir probe (Barjatya, 2007).

zero, and the plasma potential $\left(V_{\mathrm{p}}\right)$ is the potential at which no fields/sheath exist between the probe surface and the surrounding plasma. A potential lower than $V_{\mathrm{p}}$ repels electrons and higher than $V_{\mathrm{p}}$ repels ions. In theoretical expressions of collected current, plasma response is relative to $V_{\mathrm{p}}$. For a conductive body immersed in thermal plasma, $V_{\mathrm{f}}$ is negative with respect to $V_{\mathrm{p}}$, as shown in the figure.

Although the current collection of expressions depends on applied potential relative to plasma potential, in practice the potential bias applied to the probe is relative to electrical ground. Instrument ground is connected to the payload structure, so signal ground is the same as the payload floating potential. If not accounted for in data analysis of a Langmuir probe dataset, any movement in the $V_{\mathrm{f}}$, i.e. spacecraft charging, affects the accuracy of derived plasma parameters. The payload floating potential is a result of current balance. Collected currents from exposed potentials, such as Langmuir probes, have to be balanced by return currents from the payload chassis ground, or oppositely biased probes. In a typical ionospheric plasma the collected currents depend on plasma temperature and $V_{\mathrm{f}}$ for a conductive body does not charge more negative than a few tenths of a volt. Additional currents emitted from the payload such as photoelectron currents or secondary emission due to energetic particle impacts can complicate the current balance problem. For ECOMA 7, 8 and 9, all flights were at nighttime with no auroral activity, thus simplifying the situation analysis. But spacecraft charging is also a function of area ratio between the payload surface area and the probe surface area. This is because any current(s) being collected by the probe(s) has to return to the plasma through the chassis ground which is the payload surface. Ideally a payload-to-probe surface area ratio of 10000 or larger is required to remove any charging effects due to insufficient area for current return (Szuszczewicz, 1972). Such a ratio is hard to attain on sounding rockets, not only be- cause of minimum size limitations on probes, but also because there are typically multiple probes with exposed potentials. Therefore, knowledge of payload charging, and the various processes which contribute to payload charging, is crucial for proper analysis of sounding rocket instruments using typical Langmuir probes. Lai (1998) has presented three of the most common measurement techniques for spacecraft charging: floating probes mounted on long booms, measurement of the energy shift in charged particle distribution functions, and Langmuir probes. A more comprehensive comparison of floating probes and ElectroStatic Analyzers is given in Siefring and Rodriguez (1998).

Langmuir probes can be implemented in many different ways. Two of the most common implementations are as a fixed bias probe and a sweeping bias probe. A fixed bias probe has the exposed conductor biased in the electron or ion saturation region, and the measured current can yield high time resolution of density variations, but does not allow absolute determination of the plasma density. In a sweeping bias probe the voltage on the exposed conductor is swept back and forth between the ion and electron saturation regions, and analysis of the sweep gives plasma density and electron temperature. In the next section we present a novel technique - the multi-needle Langmuir probe - to measure absolute plasma density and payload floating potential using a combination of fixed bias Langmuir probes operating in the electron saturation region. By absolute we here mean the absolute value of the density in the plasma where the probes are placed. They can be influenced, for example, by effects from bow shock or payload wake, if the boom length is not sufficient to place the booms out into undisturbed plasma. We then present the data from the ECOMA 7, 8 and 9 rocket payloads from the m-NLP and dust detector instruments. We conclude the paper with a simulation and discussion of payload charging events and any impact that they have on data analysis of fixed bias Langmuir probes in such a scenario.

\section{Deriving absolute plasma density and payload poten- tial from the multi-Needle Langmuir probe}

From Langmuir's theory (Mott-Smith and Langmuir, 1926; Chen, 1965), the current collected by a cylinder with a length $\gg$ than its radius, and a radius which is $\ll_{\mathrm{D}}$ (the Debye shielding length), and operating in the electron saturation region, is given by

$I=n_{\mathrm{e}} e A_{\mathrm{p}} \sqrt{\frac{k_{\mathrm{B}} T_{\mathrm{e}}}{2 \pi m_{\mathrm{e}}}} \frac{2}{\sqrt{\pi}} \sqrt{1+\frac{V_{\mathrm{b}}-V_{\mathrm{p}}}{V_{\mathrm{e}}}}$,

where $n_{\mathrm{e}}$ is electron density, $e$ is charge on an electron, $A_{\mathrm{p}}$ is the probe surface area, $k_{\mathrm{B}}$ is Boltzmann's constant, $T_{\mathrm{e}}$ is electron temperature, $V_{\mathrm{e}}=\frac{k_{\mathrm{B}} T_{\mathrm{e}}}{e}, m_{\mathrm{e}}$ is electron mass, $V_{\mathrm{b}}$ is the potential applied to the probe with respect to the payload floating potential $V_{\mathrm{f}}$ and $V_{\mathrm{p}}$ is the plasma potential. 


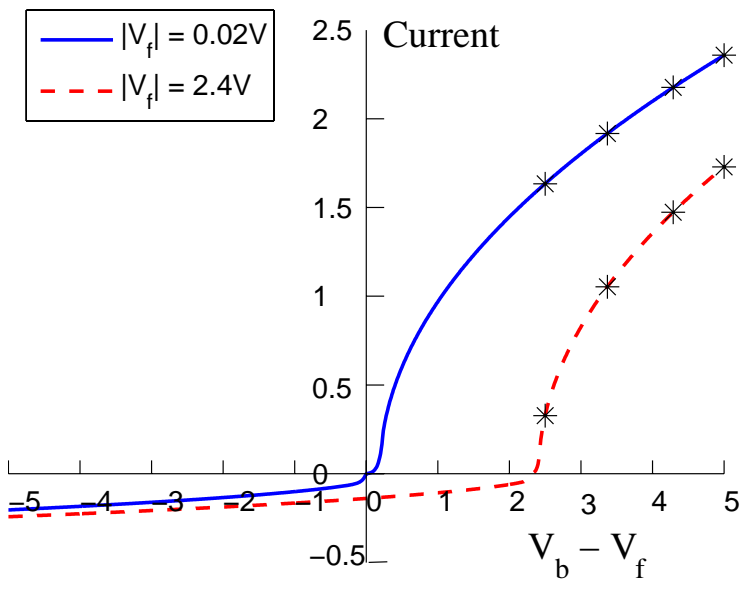

Fig. 2. In a typical ionospheric plasma, the floating potential $\left(V_{\mathrm{f}}\right)$ is no more negative than a few tenths of a volt (solid line). When the payload-to-probe surface area ratio is smaller than a few thousand, $V_{\mathrm{f}}$ charges more negative. In such a scenario a larger potential needs to be applied to the probe to operate it in the net electron current collection region; the probe voltage $\left(V_{\mathrm{b}}\right)$ relative to $V_{\mathrm{f}}$ has to be larger than $2.4 \mathrm{~V}$ to have a net electron current collection (dashed line). Also shown in each of the curves above are four points at voltages that $\mathrm{m}-\mathrm{NLP}$ was biased at, i.e. $2.5 \mathrm{~V}, 3.37 \mathrm{~V}, 4.29 \mathrm{~V}$ and $5 \mathrm{~V}$. In the case where the payload is charged more negative than about $2.4 \mathrm{~V}$, we can no longer use the $2.5 \mathrm{~V}$ needle data as representing a measurement in the saturation region.

For a cylindrical probe operated in the electron saturation region, there is a linear relationship between the square of the collected current $I^{2}$ and the applied bias voltage $V_{\mathrm{b}}$ (Jacobsen et al., 2010). Thus if we make two measurements in the electron saturation region, the difference in the square of the current at those two points is given by

$I_{2}^{2}-I_{1}^{2}=\left(C n_{\mathrm{e}} A_{\mathrm{p}}\right)^{2}\left(V_{\mathrm{b} 2}-V_{\mathrm{b} 1}\right)$,

where $C$ is a constant given by $\frac{e^{3 / 2}}{\pi} \sqrt{\frac{2}{m_{\mathrm{e}}}}$. From this we get the following:

$n_{\mathrm{e}}=\frac{1}{C A_{\mathrm{p}}} \sqrt{\frac{I_{2}^{2}-I_{1}^{2}}{V_{\mathrm{b} 2}-V_{\mathrm{b} 1}}}$.

In Eq. (3) it is important to note that the derivation of absolute density does not depend on probe potential relative to plasma potential, but depends only on the potential difference between the two needles, given that the needles are co-located. This effectively makes the m-NLP instrument immune to payload charging effects as long as the charging is not so severe that the operation of the needles is brought into the electron retardation region (see Fig. 2).

Equation (1) can also be used to find $V_{\mathrm{f}}$, the floating potential of the rocket payload, which is used as the reference for the probe bias voltage $V_{\mathrm{b}}$.

$R=\left(\frac{I_{2}}{I_{1}}\right)^{2}=\frac{V_{\mathrm{e}}+V_{\mathrm{b} 2}-V_{\mathrm{f}}}{V_{\mathrm{e}}+V_{\mathrm{b} 1}-V_{\mathrm{f}}}$
This gives the following equation for calculation of the floating potential of the platform, $V_{\mathrm{f}}$ :

$V_{\mathrm{f}}=\frac{\left(R V_{\mathrm{b} 1}\right)-V_{\mathrm{b} 2}}{R-1}+V_{\mathrm{e}}$.

By Eq. (5) we see that the platform potential can be derived by the two known bias voltages and the collected current by the biased probes. For the equations to be valid the probes must be operated in the electron saturation region. The only unknown term in Eq. (5) is $V_{\mathrm{e}}$ which depends on electron temperature $T_{\mathrm{e}}$. In the mesosphere region during winter conditions, $T_{\mathrm{e}}$ is expected to range from $200 \mathrm{~K}$ to at maximum $600 \mathrm{~K}$. Assuming $T_{\mathrm{e}}=200 \mathrm{~K}$, the term $V_{\mathrm{e}}$ will be $17 \mathrm{mV}$, and for $T_{\mathrm{e}}=600 \mathrm{~K}$ the term $V_{\mathrm{e}}=52 \mathrm{mV}$. In our calculations we have used $T_{\mathrm{e}}=400 \mathrm{~K}$ which gives $V_{\mathrm{e}}=34 \mathrm{mV}$. Thus, at worst, the error in $V_{\mathrm{f}}$ calculation due to unknown $T_{\mathrm{e}}$ will be on the order of few tens of $\mathrm{mV}$.

The multi-Needle Langmuir Probe system (m-NLP) used on the ECOMA sounding rockets, was an adapted version of the m-NLP system flown in the ICI-2 sounding rocket payload in 2008 (Bekkeng et al., 2010). The Langmuir probes are biased relative to the floating platform potential, so it is essential that the probes are biased to a voltage that is above the plasma potential, to ensure that the probes are operated in the electron saturation region. The detailed theory behind the multi-Needle Langmuir Probe concept is found in Jacobsen et al. (2010). The advantage of this technique is that as long as the probes are operated in the electron saturation region, we do not need to know the payload potential to derive absolute plasma density. All that is needed is a known potential difference between the multiple needles.

\section{The instrumentation for the ECOMA payloads}

The ECOMA rockets have a two-stage motor configuration consisting of a Nike first stage motor, and an Improved Orion second stage motor. The payload configuration after motor separation is shown in Fig. 3.

From the front of the payload we are presenting data from the ECOMA Particle detector which is a Faraday cup combined with a Xe-flash lamp. See also Rapp et al. (2012) for more details of the ECOMA Particle detector measurements during the three discussed flights. Two biases are used to shield the cup against ambient electrons and positive ions. Heavy particles will pass through these grids due to their large kinetic energy, and a very sensitive electrometer can measure if the particles have a charge (Rapp and Strelnikova, 2009).

From the aft section of the payload we have used data from the multi-Needle Langmuir Probe (m-NLP). The $\mathrm{m}$ NLP instrument consisted of four miniaturized cylindrical Langmuir probes, with a diameter of $0.51 \mathrm{~mm}$ and a length of $25 \mathrm{~mm}$. The probes biased at $+2.5 \mathrm{~V}$ and $+3.37 \mathrm{~V}$ were mounted on one boom on the aft deck of the payload. The 


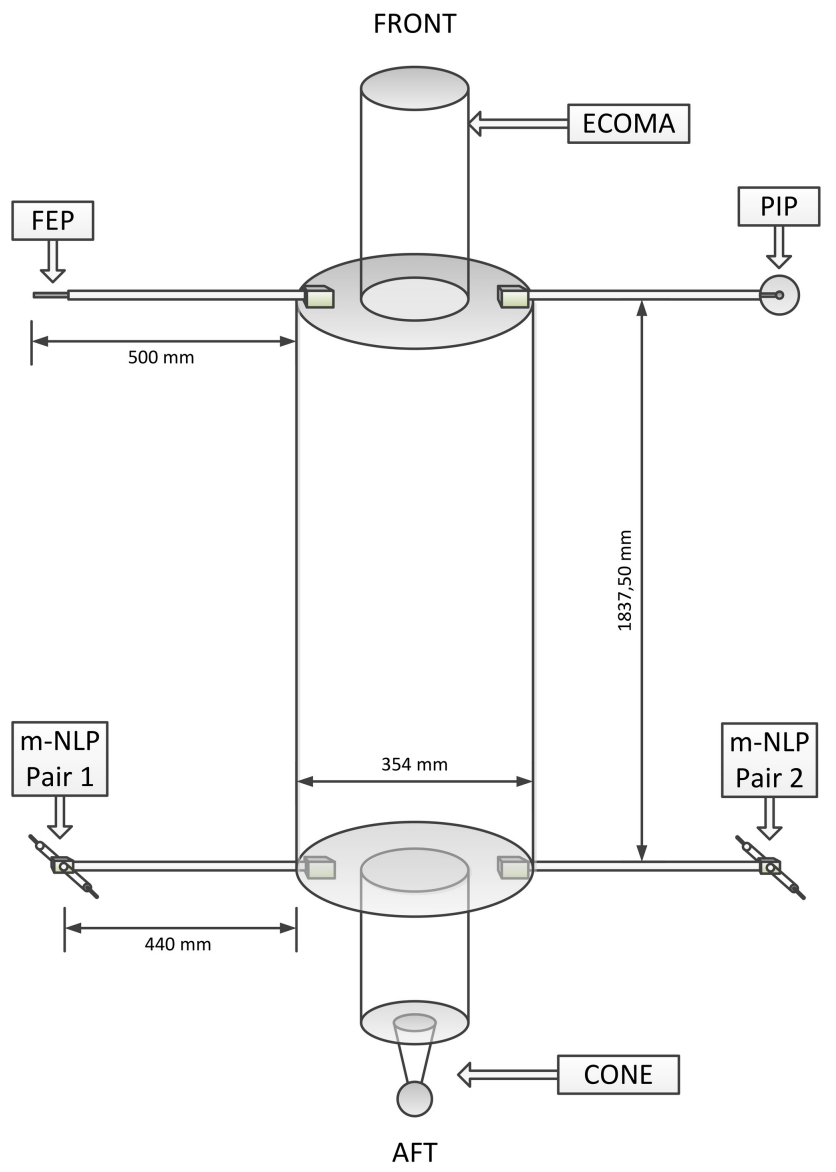

Fig. 3. ECOMA payload configuration.

other two probes biased at $+4.29 \mathrm{~V}$ and $+5.0 \mathrm{~V}$ were placed on another boom, mounted 180 degrees from the boom with the other probes. Tip to tip separation between the probes on each boom was approximately $30 \mathrm{~cm}$. The $\mathrm{m}-\mathrm{NLP}$ concept was described in the previous section of this paper. In addition to using the four needles for calculation of absolute plasma density, each of the needles can also be used as a fixed bias Langmuir probe.

In the electron density calculations presented in the next section, we have used data from the probes biased at $+3.37 \mathrm{~V}$ and $+5.0 \mathrm{~V}$. As we will show later, the payload charging was observed to be more negative than $-2 \mathrm{~V}$. In such a case, the probe biased at $+2.5 \mathrm{~V}$ is expected to get influenced and no longer operate in the electron saturation region (see Fig. 2). Therefore, we omit data from the $+2.5 \mathrm{~V}$ biased probe on all flights. In addition we unfortunately had to omit the data from the $+4.29 \mathrm{~V}$ biased probe, since it suffered from an abnormal behavior. We are in the process of determining the reason for this needle's failure on all three payloads. It is important to note that the $+3.37 \mathrm{~V}$ needle and the $+5.0 \mathrm{~V}$ needle were on opposing booms, and therefore in different wake/bow shock conditions. In order to combine their data to derive plasma density, we filtered out the spin modulation as the payload spin frequency was very well known and constant throughout the ballistic trajectory.

\section{Measured plasma densities and payload potentials}

In this section we present absolute plasma density and payload potential observations on all three rocket payloads as derived from the m-NLP measurements. These measurements were made both on the upleg and downleg part of the trajectory, although measurements in the lower altitude regions are limited by signal-to-noise ratio of the instrument which depends on ambient plasma density. We also present observations of charged mesospheric dust particles as measured by the ECOMA Particle detector. The details of this detector can be found in Rapp et al. (2012). Finally, we also use the $2.5 \mathrm{~V}$ and $5.0 \mathrm{~V}$ needle measurements as proxy for two fixed bias Langmuir probes operating at different voltages within the electron saturation region. The currents measured by the $+2.5 \mathrm{~V}$ probe and the $+5.0 \mathrm{~V}$ probe have been normalized to the m-NLP electron density at $130 \mathrm{~km}$ altitude on both upleg and downleg.

In the plots showing the density of charged meteoric dust particles, the profile shows negative charged dust up to a certain altitude. At larger altitudes, the profiles all turn to positive values and remain positive until apogee at $\sim 130 \mathrm{~km}$; here only shown up to $\sim 105 \mathrm{~km}$. Rapp et al. (2012) goes into a detailed discussion on this, and suspects that these positive signatures are not evidence of positively charged particles but likely contamination of measurements by leakage currents from positive ions. These signatures are therefore not discussed in this paper.

\subsection{ECOMA 7}

ECOMA 7 was launched on 4 December 2010 at 05:21 LT (04:21 UTC) to get background measurements of the conditions very early in the Geminids meteor shower. (See Stober et al., 2013, for a detailed discussion of the time evolution of this shower.) As shown in Fig. 4 (upleg) and Fig. 5 (downleg) the electron density in the D-layer was one of the lowest recorded by sounding rockets in northern latitudes in the last decades (Friedrich et al., 2013). Due to this, the signal-tonoise ratio (SNR) of the measured currents from the probes are too low to get a good calculation of the platform potential below an altitude of about $88 \mathrm{~km}$ on both upleg and downleg. An overall look of the upleg and downleg portion of the trajectory shows that the average payload floating potential is about $-2 \mathrm{~V}$, but within the $100 \mathrm{~km}$ to $110 \mathrm{~km}$ region on the upleg the payload experienced a charging event wherein the payload potential moved less negative. This event can possibly be driven by weak auroral precipitation, although no clear signature of auroral activity is seen in allsky images from Andøya during the launch of ECOMA 7. Between $95 \mathrm{~km}$ and $99 \mathrm{~km}$ a sporadic E-layer is seen on both upleg and downleg. 

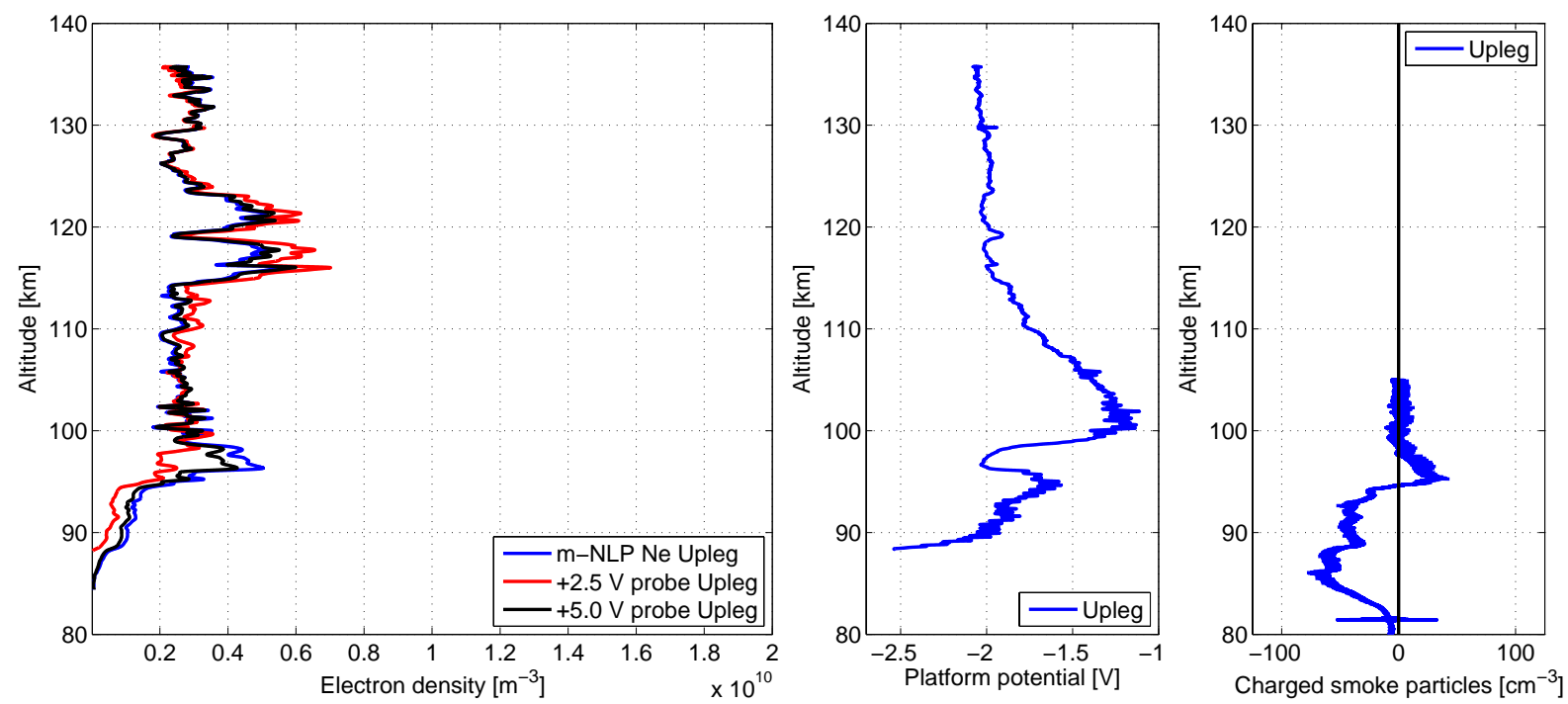

Fig. 4. Electron density (left), platform potential (center) and charged smoke particles (right) for ECOMA 7 plotted against height on upleg.
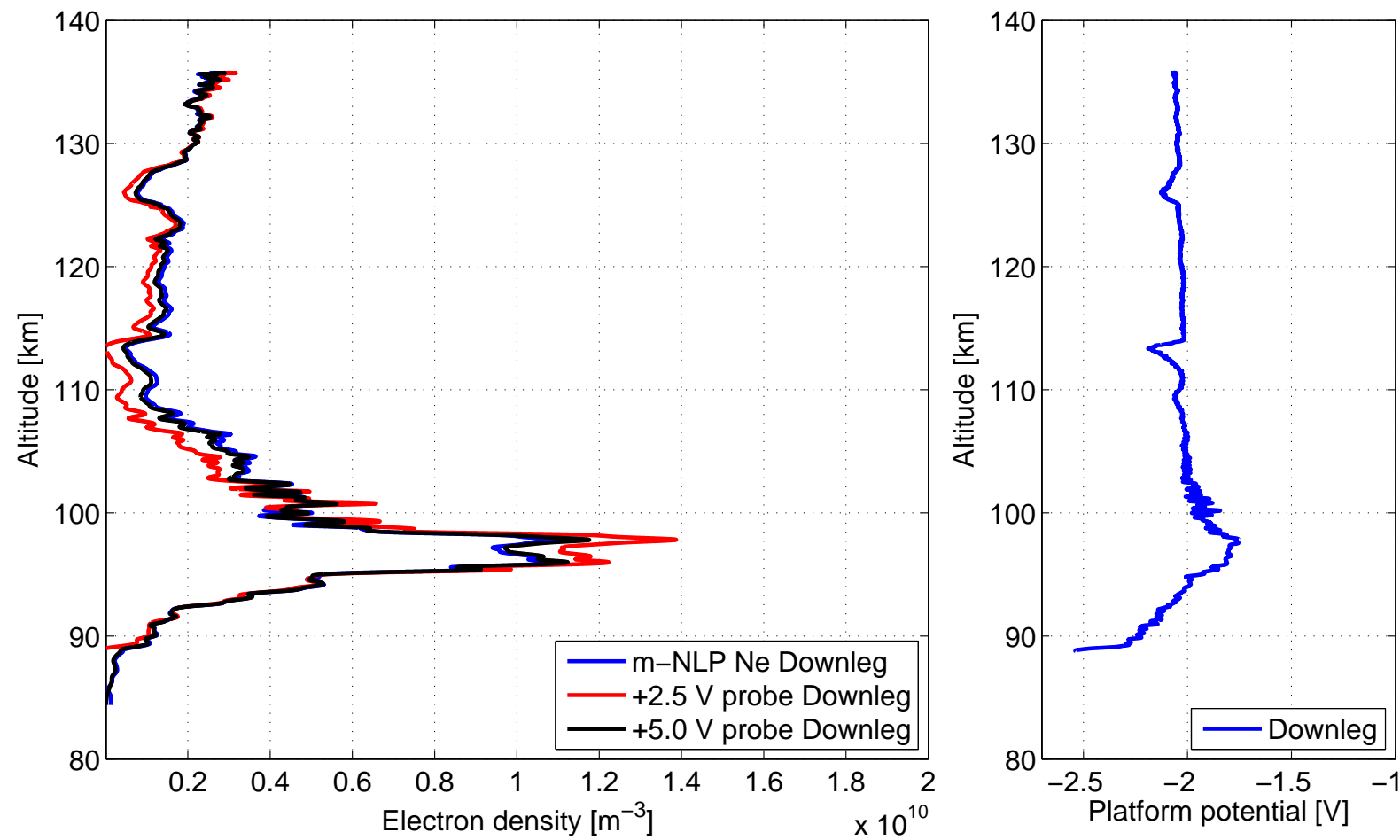

Fig. 5. Electron density (left) and platform potential (right) for ECOMA 7 plotted against height on downleg.

\subsection{ECOMA 8}

ECOMA 8 was launched on 13 December 2010 at 04:24 LT (03:24 UTC) at the peak of the Geminids. Here the peak value of the electron density was about 20 times higher than for ECOMA 7, as shown in Figs. 6 and 7. This results in a higher SNR for the current measurements from the Langmuir probes, enabling good determination of $V_{\mathrm{f}}$ above $84 \mathrm{~km}$ altitude on the upleg, and down to $80 \mathrm{~km}$ altitude on the downleg. Allsky images from Andøya during the launch of ECOMA 8 shows signatures of weak auroral activity.

At $87 \mathrm{~km}$ altitude on the upleg, the data from the ECOMA particle detector shows a concentration of 100 negatively charged smoke particles per cubic centimeter. This increase in negatively charged MSPs is presumed to come from electrons adsorbed on the MSPs. In the platform potential data 

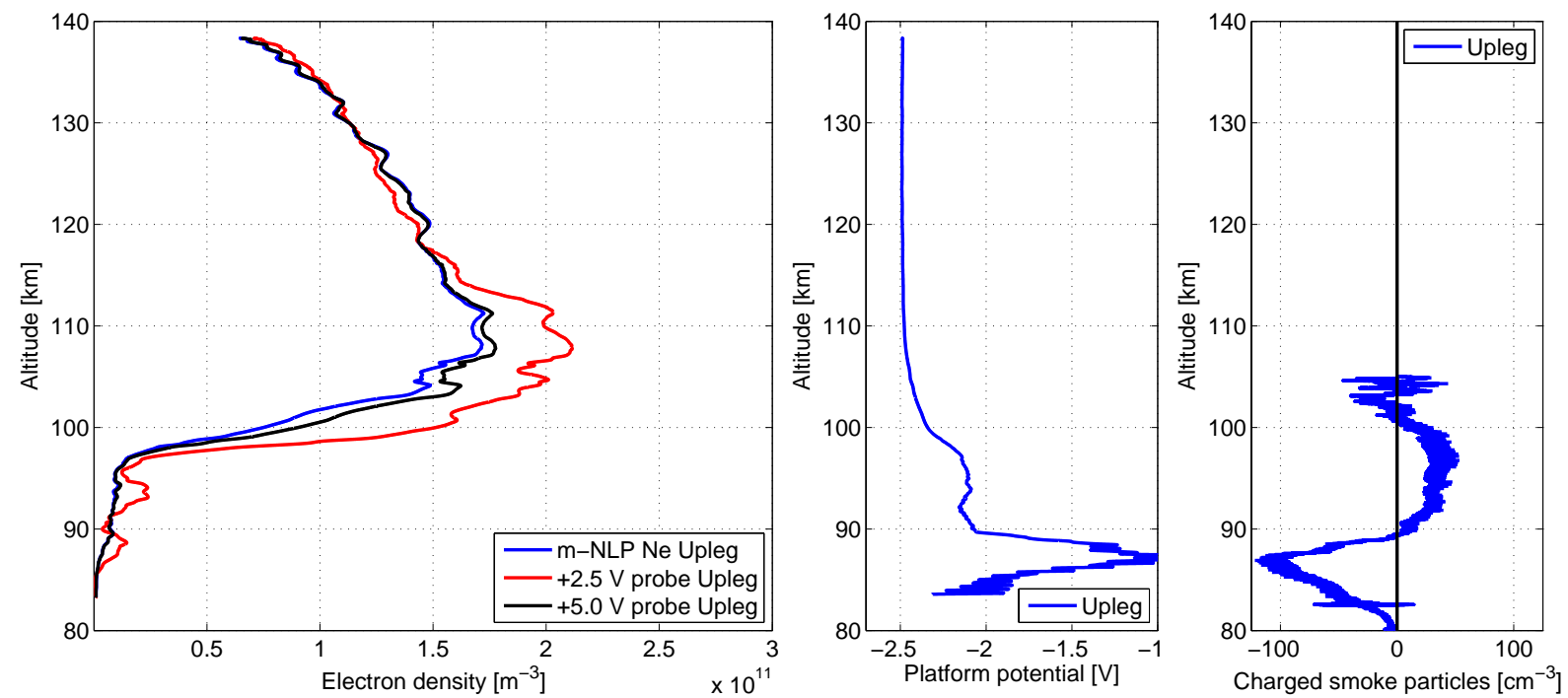

Fig. 6. Electron density (left), platform potential (center) and charged smoke particles (right) for ECOMA 8 plotted against height on upleg.
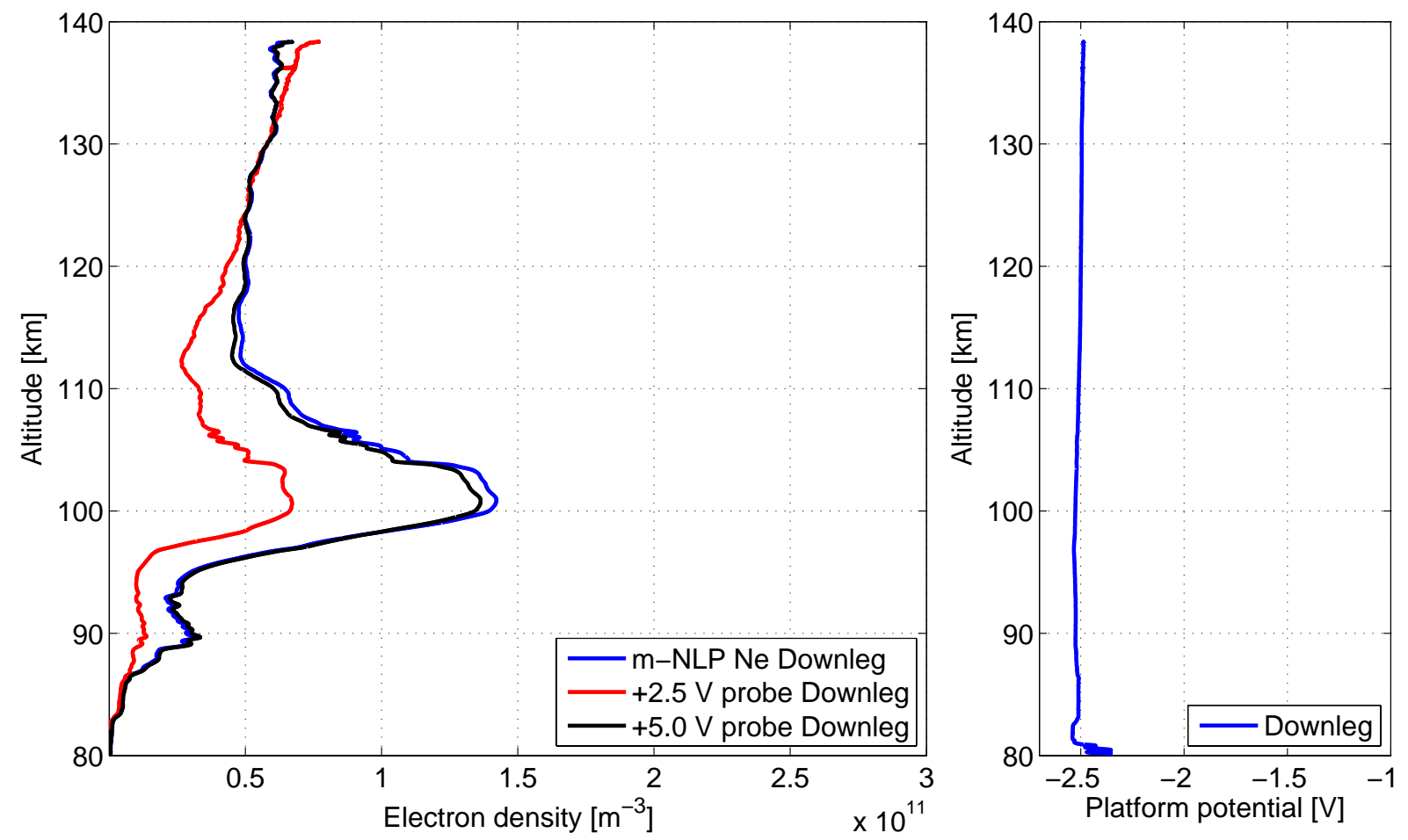

Fig. 7. Electron density (left) and platform potential (right) for ECOMA 8 plotted against height on downleg.

we see that the payload potential goes from $\sim-2 \mathrm{~V}$ at $84 \mathrm{~km}$ altitude, and up to $\sim-1 \mathrm{~V}$ at $87 \mathrm{~km}$ altitude, before decreasing down to $\sim-2.5 \mathrm{~V}$ for the rest of the flight. Due to insufficient SNR below $84.5 \mathrm{~km}$, on the upleg we do not have platform potential data to cover the entire structure of negatively charged MSPs between 81 and $89 \mathrm{~km}$ altitude.

\subsection{ECOMА 9}

ECOMA 9 was launched on 19 December 2010 at 03:36 LT (02:36 UTC) to get a background measurement after the meteor shower had ended. The electron densities are slightly lower in magnitude compared to ECOMA 8. An increase in negatively charged MSPs was observed on ECOMA 9 between 80 and $87 \mathrm{~km}$, which is comparable to the quantities 

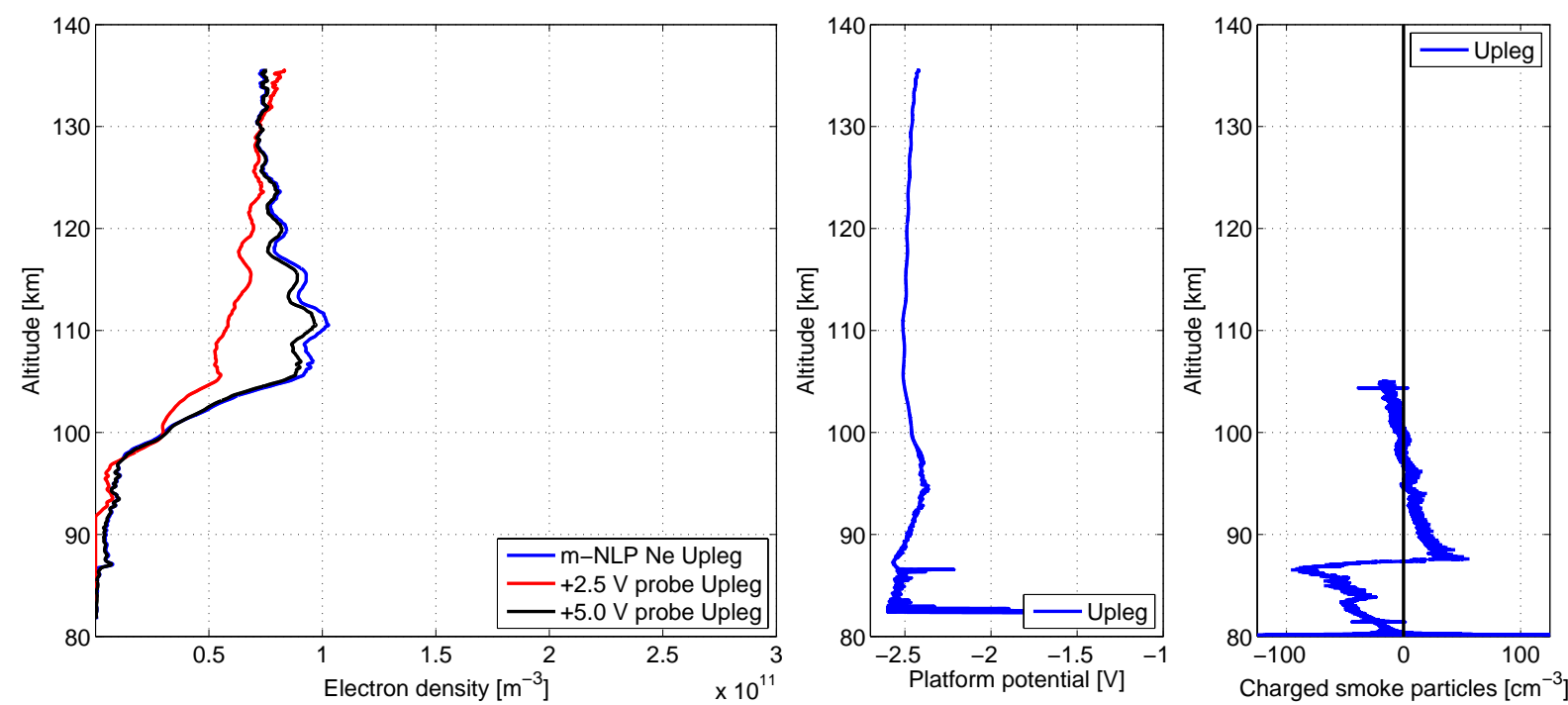

Fig. 8. Electron density (left), platform potential (center) and charged smoke particles (right) for ECOMA 9 plotted against height on upleg.


Fig. 9. Electron density (left) and platform potential (right) for ECOMA 9 plotted against height on downleg.

during ECOMA 8. At the peak of this feature where the quantity of negatively charged MSPs is at its largest, we see a response where the platform potential goes less negative. Below $90 \mathrm{~km}$ altitude on upleg the electron density is more than twice as high on ECOMA 9 than on ECOMA 8. The payload maintained a fairly stable negative floating potential at around $-2.4 \mathrm{~V}$, except around $87 \mathrm{~km}$ where the payload potential goes less negative.

\section{Discussion}

In a quasi-neutral Maxwellian plasma, electron thermal current collected by a conductive body is two orders of magnitude larger than the ion thermal current. Thus in a typical mesosphere/ionosphere nighttime (darkness) plasma, any conductive body attains a negative floating potential such that the ion and electron collected currents sum to zero, and the 


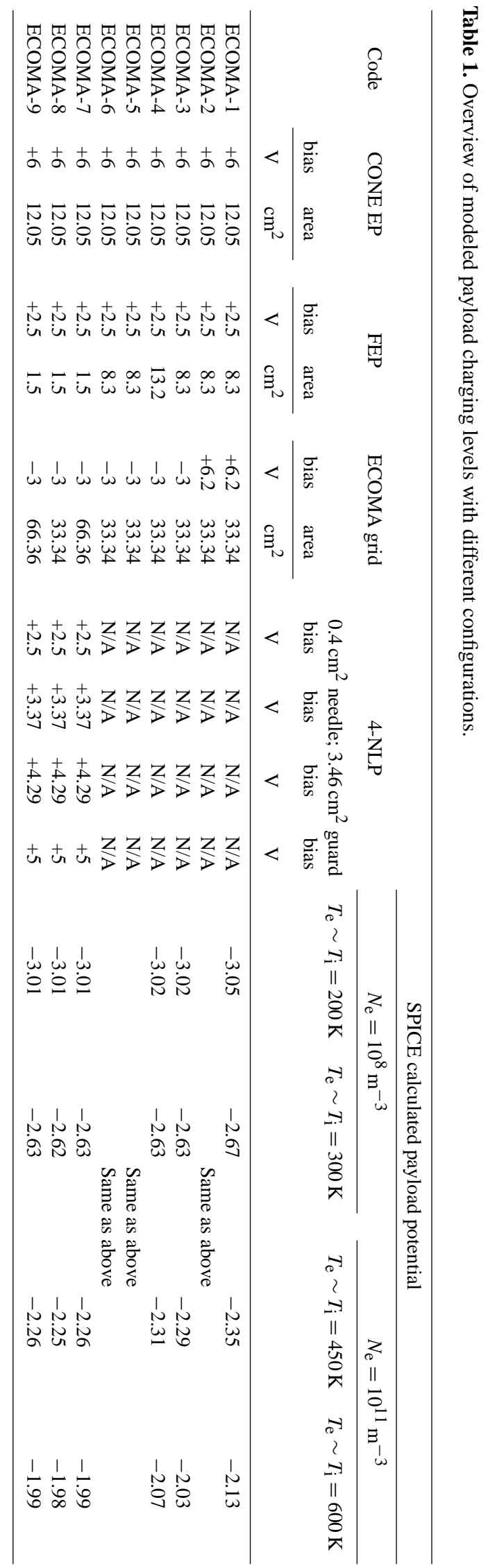

floating potential varies from $-0.1 \mathrm{~V}$ to $-0.6 \mathrm{~V}$ depending on electron temperature. A rocket payload can charge significantly differently if there are exposed potentials on its surface which collect additional electrons (payload charges more negative) or emits photoelectrons or secondary emission electrons (payload charges more positive). On all three ECOMA (7, 8 and 9) flights, the average level of payload potential ranges from -2 to $-2.5 \mathrm{~V}$. Additionally on both the ECOMA 7 and 8 flight, there is an altitude region where the payload potential changes by $50 \%$. In order to understand the payload charging for all three flights, we first model the expected payload charging which includes all the exposed potentials on the rocket payload.

We use a SPICE (Simulation Program with Integrated Circuit Emphasis) simulation to model payload charging, similar to that used by Barjatya and Swenson (2006). We model the ECOMA payloads as cylindrical surfaces using dimensions from the payload drawings. We then include within the model those sensors which have exposed biased surfaces that could be a source of additional electron current collection. The Combined Observation of Neutrals and Electrons (CONE) instrument includes a gridded sphere (Giebler et al., 1993) mounted in the aft end of the payload. Getting the collection area for CONE right is very important since the payload surface charging is strongly dependent on the area that is collecting additional currents beyond the thermal currents. Furthermore, the CONE outer grid was biased at $+6 \mathrm{~V}$ which results in a large electron current collection and therefore has a significant impact on payload charging. Based on sensor mechanical drawings, we have treated the CONE gridded sphere to have $89 \%$ transparency. The m-NLP probes were deployed on booms and each needle had a guard on one side which was applied the same potential as the needle. We also include the fixed bias Forward Electron Probe (FEP) as a cylindrical probe and the ECOMA detector as a planar probe. Although the ECOMA detector has a larger collection area than other probes, its impact on payload charging is expected to be low as it is biased in the ion saturation region. The platform floating potential was calculated for all nine ECOMA payloads (See Rapp et al. (2011) for a summary of the previous ECOMA rocket flights). But only ECOMA 7, 8 and 9 carried the m-NLP instrument that measured the payload potential in situ. The results from the simulations are shown in Table 1. We have used two different electron densities and four different electron temperatures for our simulations, shown in the four rightmost columns of Table 1 . The areas used for each instrument, and the potentials applied to each instrument are also shown in the table.

The accuracy of the simulation is limited by the accuracy of the various known areas, but the uncertainties in these areas are small enough to be neglected. Nevertheless, the simulation shows that the payload should be charging anywhere from -2 to $-3 \mathrm{~V}$ depending on the ambient plasma temperature. These values are not far from what was observed in situ by m-NLP as shown in Figs. 4-9. As is evident from the 
table, while the instrumentation on each ECOMA payload remained the same, the areas and potential applied across various instruments changed. Most notable is the fact that the ECOMA (i.e. charged dust detector) outer grid was initially set to $+6.2 \mathrm{~V}$ during ECOMA 1 and 2 flights. This was changed in later ECOMA flights to operate in the ion saturation region instead and biased at $-3 \mathrm{~V}$. Similarly, the dimensions of FEP were also changed amongst various ECOMA flights. It should be noted that for lower plasma temperatures the simulation shows no difference between ECOMA3 through ECOMA-9 charging levels even though the size of FEP varied significantly. This is simply because for the lower temperatures the payload is already charging negative enough that the FEP is no longer in the electron saturation region to collect much electron current and therefore affect charging.

The SPICE simulations explain the average charging levels of -2 to $-2.5 \mathrm{~V}$ seen on the three flights. The simulations do not explain the positive charging events (i.e. from -2 to $-1 \mathrm{~V}$ ) on the upleg portion of ECOMA 7 and 8. The rockets were launched in darkness and when there was no auroral activity. Therefore, we can safely rule out positive charging due to photoelectron emission or secondary electron emission. Barjatya and Swenson (2006) have also reported charging events in the mesosphere correlated with the presence of charged dust particles. They postulated and simulated that this unexpected charging is due to triboelectric current transfer between neutral dust/smoke particles and the payload surface. These neutral particles accompany and outnumber the observed heavier charged dust. They further theorized that the charging could either be negative or positive depending on the work function difference between the neutral smoke particles and the payload surface. In the flight data analyzed in Barjatya and Swenson (2006), the payload charged more negative indicating the neutral smoke/dust was a source of additional electron current to the payload surface. As an example of an event where the neutral smoke/dust could be a sink to the electrons from the payload surface and thus charge the payload positive, they pointed to Gelinas et al. (2005). They presented data from the DUST campaign, and a scenario in which the payload floating potential moved positive. This pushed the fixed bias Langmuir probe further into the saturation region, which then indicated an increase in the plasma density as shown in Fig. 5 in Gelinas et al. (2005). This scenario could, however, not be confirmed on that rocket flight due to lack of measurement of payload floating potential. However, on ECOMA 7, we see just such a case. As shown in Fig. 5, if one were to use the $2.5 \mathrm{~V}$ m-NLP needle as representing a fixed bias Langmuir probe, then the region where the payload potential moves less negative shows up as an increase in the density profile derived using the $2.5 \mathrm{~V}$ needle (red line). The $2.5 \mathrm{~V}$ m-NLP needle on ECOMA 9 shows that the normalized density profile is significantly lower than the calculated electron density on upleg, where the payload potential is $-2.5 \mathrm{~V}$. On the downleg on ECOMA 9 the pay- load potential moves less negative, to about $-2.25 \mathrm{~V}$. This shift in payload potential moves the $2.5 \mathrm{~V}$ m-NLP needle more into the electron saturation region, giving a more correct density profile. In other words, Figs. 4-9 caution us from using fixed bias Langmuir probes that are not biased far into the electron saturation region and can therefore be easily influenced by a few volts movement in payload floating potential. As compared to the absolute density derived from the cumulative m-NLP instrument, the $5 \mathrm{~V}$ needle is shown to be only marginally $(<5 \%$ at worst) influenced while the $2.5 \mathrm{~V}$ needle is heavily influenced. Furthermore, these plots also show that sounding rocket payloads that carry a fixed bias Langmuir probe should also carry instruments to measure the payload floating potential and to measure the absolute density from some other means such as a Faraday rotation or impedance probes, which are known to be immune to spacecraft charging.

In addition to the positive charging events observed on the upleg of ECOMA 7 and 8, of particular interest is the lack of such charging events on the downleg of ECOMA 7 and 8. This is in contrast to Barjatya and Swenson (2006) who observed charging events on both upleg and downleg portions of the payload trajectory. If these charging events are indeed due to triboelectric charge transfer from neutral dust/smoke particles, then the intermittent nature of these charging events is representative of patchiness of these layers.

\section{Conclusions}

We have presented and compared the measured electron density, payload potential and charged dust for all three ECOMA 7, 8 and 9 rocket launches. The charging features within the lower mesosphere observed on ECOMA 7 and 8 , where the payload potential changes by $50 \%$, cannot be explained by a simple SPICE model. When comparing the quantities of charged smoke particles on ECOMA 9 to the quantities on ECOMA 8, we would expect to see a similar feature of decrease in payload potential on ECOMA 9 as we observed on ECOMA 8. A small feature is seen on ECOMA 9, but it is significantly smaller than the feature on ECOMA 8. We cannot offer a concrete explanation for this difference, or the lack of features on the downleg portion of ECOMA 7 and 8. We can only attribute them to the patchiness or other variability (such as particle composition) of these smoke/dust layers.

From the data presented in this paper we can conclude that measurements from fixed bias Langmuir probes can show density enhancements or depletions within the density profile that could be an artifact of payload charging. Our results emphasize that every payload that flies a fixed bias Langmuir probe should also fly an instrument that can measure the charging of the payload. The multi-Needle Langmuir probe technique is the only non-sweeping Langmuir probe technique which can give absolute density independent of 
payload charging, as long as the bias levels are ensured to be sufficiently above the plasma potential and the needle diameter smaller than the Debye length. As shown, theoretically we can get the floating potential within a few percent, but it is not possible to confirm this in light of any other corroborating measurements on ECOMA flights. However, as limited as it is, the SPICE model simulations do show that the m-NLP measurements are within $30 \%$ of what is to be expected. A Faraday rotation or impedance probe can also give absolute density that is immune to payload charging effects, even if it is at a low spatial sampling rate (Mechtly et al., 1967). The superiority of the classic Faraday rotation experiment is that it is not susceptible to sheath effects around the spacecraft body.

Acknowledgements. The Norwegian Space Centre and the Research Council of Norway supported the Norwegian contribution to the ECOMA programme under grants 197629 and 191754. ESA supported the development of the multi-Needle Langmuir Probe instrument under PRODEX Arrangement No 90335.

Topical Editor C. Jacobi thanks O. Havnes and K. Lynch for their help in evaluating this paper.

\section{References}

Barjatya, A.: Langmuir Probe Measurements In The Ionosphere, Ph.D. dissertation, All Graduate Theses and Dissertations, Utah State University, Paper 274, 2007.

Barjatya, A. and Swenson, C. M.: Observations of triboelectric charging effects on Langmuir type probes in dusty plasma, J. Geophys. Res., 111, A10302, doi:10.1029/2006JA011806, 2006.

Barjatya, A., Swenson, C. M., Thompson, D. C., and Wright, J. K. H.: Data analysis of the floating potential measurement unit aboard the international space station, Rev. Sci. Instrum., 80, 041301, doi:10.1063/1.3116085, 2009.

Bekkeng, T. A., Jacobsen, K. S., Bekkeng, J. K., Pedersen, A., Lindem, T., Lebreton, J.-P., and Moen, J. I.: Design of a multi-needle Langmuir probes system, Meas. Sci. Technol., 21, 085903, doi:10.1088/0957-0233/21/8/085903, 2010.

Brace, L. H.: Langmuir probe measurements in the ionosphere, Measurement Techniques in Space Plasmas: Particles, Geophysical Monograph Series, American Geophysical Union, 102, 2335, 2000.

Braithwaite, N. S. J. and Franklin, R. N.: Reflections on electrical probes, Plasma Sources Sci. Technol., 18, 014008, doi:10.1088/0963-0252/18/1/014008, 2009.

Chapkunov, S. K., Ivanova, T. N., Petrunova, M. K., and Serafimov, K. B.: Measurement of electron and ion density and temperature on the INTERCOSMOS 12 satellite, Space research XVI; Proceedings of the Open Meetings of Working Groups on Physical Sciences, 29 May-7 June, pp. 423-425, 1976.

Chen, F. F.: Electric probes, Plasma Diagnostic Techniques (Academic Press), 113-200, 1965.
Friedrich, M., Torkar, K. M., Hoppe, U.-P., Bekkeng, T.-A., Barjatya, A., and Rapp, M.: Multi-instrument comparisons of Dregion plasma measurements, Ann. Geophys., 31, 135-144, doi:10.5194/angeo-31-135-2013, 2013.

Gelinas, L., Lynch, K., Kelley, M., Collins, R., Widholm, M., MacDonald, E., Ulwick, J., and Mace, P.: Mesospheric charged dust layer: Implications for neutral chemistry, J. Geophys. Res., 110, A01310, doi:10.1029/2004JA010503, 2005.

Giebler, J., Lübken, F.-J., and Nägele, M.: CONE - a new sensor for in-situ observations of neutral and plasma density fluctuations, Proceedings of the 11th ESA Symposium on European Rocket and Balloon Programmes and related research, Montreaux, Switzerland, ESA-SP-355, 311-318, 1993.

Jacobsen, K. S., Pedersen, A., Moen, J. I., and Bekkeng, T. A.: A new Langmuir probe concept for rapid sampling of space plasma electron density, Meas. Sci. Technol., 21, 085902, doi:10.1088/0957-0233/21/8/085902, 2010.

Lai, S. T.: A Critical Overview of Measurement Techniques of Spacecraft Charging in Space Plasma, Geophysical Monograph (AGU), 103, 217-221, 2000.

Mechtly, E. A., Bowhill, S. A., Smith, L. G., and Knoebel, H. W.: Lower Ionosphere Electron Concentration and Collision Frequency from Rocket Measurements of Faraday Rotation, Differential Absorption, and Probe Current, J. Geophys. Res., 72, 5239-5245, 1967.

Mott-Smith, H. M. and Langmuir, I.: The theory of collectors in gaseous discharges, Phys. Rev., 28, 727-763, 1926.

Rapp, M. and Strelnikova, I.: Measurements of meteor smoke particles during the ECOMA-2006 campaign: 1. particle detection by active photoionization, J. Atmos. Sol. Terr. Phys., 71, 477-485, 2009.

Rapp, M., Strelnikova, I., Strelnikov, B., Friedrich, M., Gumbel, J., Hoppe, U.-P., Blix, T., Havnes, O., Bracikowski, P., Lynch, K., and Knappmiller, S.: Microphysical properties of mesospheric aerosols: An overview of in situ-results from the ECOMA project, Aeronomy of the Earths Atmosphere and Ionosphere, Springer Science+Business Media B. V., edited by: Abdu, M. A., Pancheva, D., and Bhattacharyya, A., IAGA Special Sopron Book Series, pp. 67-74, doi:10.1007/978-94-007-0326-1_4, 2011.

Rapp, M., Plane, J. M. C., Strelnikov, B., Stober, G., Ernst, S., Hedin, J., Friedrich, M., and Hoppe, U.-P.: In situ observations of meteor smoke particles (MSP) during the Geminids 2010: constraints on MSP size, work function and composition, Ann. Geophys., 30, 1661-1673, doi:10.5194/angeo-30-1661-2012, 2012.

Siefring, C. L. and Rodriguez, P.: Results from the NRL Floating Probe on SPEAR III: High Time Resolution Measurements of Payload Potential, Geophysical Monograph (AGU), 103, 223228, 2000.

Stober, G., Schult, C., Baumann, C., Latteck, R., and Rapp, M.: The Geminid Meteor Shower during the ECOMA Sounding Rocket Campaign: specular and head echo radar observations, Ann. Geophys., in review, 2013.

Szuszczewicz, E. P.: Area influences and floating potentials in Langmuir probe measurements, J. Appl. Phys., 43, 874-880, 1972. 